\title{
Genes de resistencia en bacilos Gram negativos: Impacto en la salud pública en Colombia
}

\author{
Resistance genes in gram negative bacilli: Impact on public health in Colombia
}

Diana Paola López-Velandia', María Inés Torres-Caycedo², Carlos Fernando Prada-Quiroga³

1 Bacterióloga y laboratorista clínica en Servicio Social Obligatorio. Docente auxiliar. Grupo de Investigación de Bacteriología y Laboratorio clínico, Universidad de Boyacá. Tunja, Colombia.e-mail: dplopez@uniboyaca.edu.co

2 Bacterióloga y laboratorista. Docente asociada. Maestría en Ciencias Biológicas. Directora Programa de Bacteriología y Laboratorio Clínico. Grupo de investigación de bacteriología y laboratorio clínico. Universidad de Boyacá. Tunja, Colombia. e-mail: mariaitorres@uniboyaca.edu.co

3 Biólogo, Maestría en Genética; Doctorado en genética. Líder Grupo de Investigación de Bacteriología y Laboratorio Clínico. Universidad de Boyacá. Tunja, Colombia. e-mail: cafepra@hotmail.com

López-Velandia DP, Torres-Caycedo MI, Prada- Quiroga CF. Genes de resistencia en bacilos Gram negativos: Impacto en la salud pública en Colombia. Univ. Salud. 2016;18(1):190-202. DOI: http://dx.doi.org/10.22267/rus.161801.30

\section{Resumen}

Introducción: La resistencia antimicrobiana es un grave problema de salud pública que se encuentra en aumento. Entre los factores más importantes relacionados con la diseminación de bacterias multirresistentes está el uso inapropiado de antibióticos y la aplicación insuficiente de las medidas de prevención y control. Adicionalmente, las bacterias tienen la capacidad de mutar o generar mecanismos de transferencia de genes de resistencia mediante plásmidos, transposones e integrones. Materiales y métodos: Se hizo una revisión crítica de la literatura sobre los principales genes de resistencia Gram negativos y su impacto en la salud pública. Fueron utilizadas las bases de datos de Medline, Embase, Lilacs, ScienceDirect, Scopus, SciELO, the Cochrane Library y Lilacs. Resultados: Se presenta una revisión de literatura que describe y analiza los principales genes de resistencia a antibióticos presentes en bacilos gram negativos, su origen, evolución y diseminación a microorganismos mediante la transferencia horizontal de genes; justificando la importancia de realizar una vigilancia epidemiológica del tránsito de clones con diferentes perfiles de resistencia y principales enzimas. Conclusiones: El seguimiento de la resistencia antimicrobiana desde el punto de vista de la epidemiología molecular forma parte transcendental de la vigilancia antibiótica como lo recomienda la Organización Mundial de la Salud; pues representa el futuro del monitoreo de la resistencia.

Palabras clave: Farmacorresistencia bacteriana; genes bacterianos; salud pública; transferencia de gen horizontal. (Fuente: DeCS, Bireme).

\begin{abstract}
Introduction: Antimicrobial resistance is a serious public health problem that is increasing. Among the most important factors related to the spread of multi-resistant bacteria are the inappropriate use of antibiotics and the insufficient implementation of prevention and control measures. Additionally, bacteria have the ability to mutate or create mechanisms for transfer of resistance genes via plasmids, transposons and integrons. Materials and methods: A critical review of the literature on major resistance genes in Gram negative bacteria and its impact on public health
\end{abstract}


was conducted. Data have been collected from Medline, Embase, Lilacs, ScienceDirect, Scopus, SciELO, the Cochrane Library and Lilacs. Results: A review of literature that describes and analyzes the main antibiotic resistance genes present in gram-negative bacilli is presented, as well as their origin, evolution, and subsequent spread to hundreds of species of microorganisms by Horizontal gene transfer which justifies the importance of conducting an epidemiological surveillance on transit of clones with different resistance profiles and major enzymes. Conclusions: The control of antimicrobial resistance from the point of view of molecular epidemiology is part of the antibiotic surveillance control as recommended by the World Health Organization; as it represents the future of the surveillance of resistance.

Keywords: Bacterial drug resistance; bacterial genes; public health; horizontal gene transfer. (Source: DeCS, Bireme).

\section{Introducción}

Antes de descubrimiento de la penicilina en la década de los 40's, las enfermedades infecciosas eran la principal causa de muerte del ser humano. A pesar de los avances en la medicina, las infecciones bacterianas siguen siendo un grave problema en muchos países del mundo. 1 A lo largo de la historia se ha visto aumento significativo de la resistencia bacteriana a los antimicrobianos, efecto que ha generado gran preocupación por ser el principal obstáculo en el tratamiento y en la contención de etiologías infecciosas. Siendo además, de interés para el desarrollo de nuevas estrategias terapéuticas.

La resistencia no suele ser un problema de patogénesis, sino de limitación de las opciones terapéuticas; por lo que dependemos de los antimicrobianos para el tratamiento de las infecciones, condicionado por las prácticas asistenciales, y en particular por el uso excesivo de los antimicrobianos en trastornos en los que no aportan beneficios.2-3

Esta resistencia a los antibióticos se ha asociado con el retraso en el inicio del tratamiento antibiótico apropiado, la estancia prolongada en centros hospitalarios y aumento de costos directos e indirectos para las instituciones, el paciente y la familia. Además, el aumento de las tasas de mortalidad por inicio tardío del tratamiento adecuado en pacientes con infecciones por microorganismos resistentes que significa un evento de interés en salud pública el cual requiere del máximo esfuerzo de todas las instituciones gubernamentales que garanticen su control y de instituciones en investigación que generen conocimiento y herramientas frente el tema.4-8

Problemática de mayor impacto en hospitales de alta complejidad por el número de pacientes críticamente enfermos, huéspedes inmunocomprometidos, presencia de múltiples enfermedades concomitantes y uso frecuente de dispositivos invasivos, sumado a otros factores como la selección y uso inapropiado de antibióticos, aplicación insuficiente de medidas de prevención y control, higiene de manos, protocolos de limpieza y desinfección; además de los mecanismos de resistencia intrínsecos o adquiridos por la bacteria que conllevan a la aparición de multirresistencia, capacidad que tienen las bacterias de eludir la acción antibacteriana como fenomeno inagotable, así como su alta tasa de mutaciones y su amplia gama de transferencia de material genético intra o interespecífico.9-11

La Organización Mundial de la Salud (OMS) plantea una estrategia para la contención de la resistencia a los antimicrobianos, que recomienda intervenciones para retrasar la aparición de resistencia, así como reducir su diseminación. Dicha documento prioriza la vigilancia como el primer paso y parte fundamental de esta estrategia. 12

En Colombia el estudio de la problemática de la resistencia por parte de los patógenos bacterianos hospitalarios se inició en la década de los años noventa, pero solamente hasta ésta década se han llevado estudios de forma continua que involucran descripciones de prevalencias, caracterización de fenotipos y genotipos, estudios 
de costos, vigilancia de la resistencia entre otros.5,8,13-17 Por lo tanto, este trabajo tiene como objetivo realizar una revisión sistemática sobre los principales genes de resistencia en bacilos Gram negativos y su impacto en salud pública.

\section{Materiales y métodos}

Se hizo una revisión bibliográfica sistemática sobre los principales genes de resistencia Gram negativos en las bases de datos Medline, Embase, Lilacs, ScienceDirect, Scopus; SciELO; The Cochrane Library y Lilacs. Se realizaron búsquedas en cada una de las bases de datos, utilizando todas las combinaciones posibles con las palabras claves en inglés (Bacterial Drug Resistance, Bacterial Genes, Infection, Horizontal Gene Transfer, mutation) usando el operador boleano AND. Fue estipulado un límite de fecha para las publicaciones a partir del año 2000 hasta el 2015, y considerados artículos de investigación original o de revisión, disponibles en inglés o español.

Se incluyeron estudios observacionales, estudios de vigilancia epidemiológica sobre el perfil de resistencia de las enterobacterias y su relación con el comportamiento con respecto a los diferentes genes de resistencia, de igual manera se evaluó información sobre la caracterización molecular de las enzimas responsables de la resistencia en las enterobacterias. Esta revisión es el resultado de la ejecución del proyecto de investigación denominado: "Tipificación molecular de genes de resistencia en bacilos gramnegativos asociados a infecciones de vías urinarias en una institución prestadora de servicios de salud del departamento de Boyacá".

\section{Resultados y discusión}

\section{Genes de resistencia bacteriana}

El fenómeno de resistencia tiene un origen genético natural o adquirido que se expresa fenotípicamente por mecanismos bioquímicos; principalmente observada en bacterias Gram negativas. Dichos genes de resistencia han surgido por mutación o adquisición de plásmidos (autorreplicación, ADN extracromosómico) o transposones (cromosomal o integrado en plásmidos, cassettes de ADN transmisibles), los cuales son elementos de expresión genética que incorporan genes sin promotor, de tal modo que se convierten en genes funcionales.18-20

Los genes de resistencia naturales en plásmidos, se originan como mutaciones puntuales en los genes blanco (sitios de inserción de los genes de resistencia) de bacterias susceptibles y también de genes que les proveen protección contra otras bacterias. 21

En bacilos Gram negativos los integrones han sido detectados principalmente en las familias Enterobacteriaceae y Vibrionaceae, y en algunos no fermentadores, como Pseudomonas aeruginosa y Acinetobacter baumannii.22,23 Hasta la fecha se han descrito varias familias de integrones de acuerdo a la secuencia nucleotídica del gen intI.24 Sus integrasas presentan entre $45 \%$ y $58 \%$ de homología, sugiriendo una divergencia evolutiva por un período superior a 50 años, lo que corresponde, aproximadamente, a la era antibiótica; los integrones no pueden realizar autotransposición pero se asocian frecuentemente a secuencias de inserción o bien, a transposones y plásmidos conjugativos que les sirven como vehículos para su transmisión inter e intra especie.25,26

Las enterobacterias son las causantes de aproximadamente el $30 \%$ de los aislamientos bacterianos en sangre, el $65 \%$ de los gastrointestinales, el $75 \%$ de los del tracto urinario, y son responsables de más del $30 \%$ de las infecciones respiratorias de vías bajas en pacientes con riesgo de colonización de orofaringe.3 La Sociedad Americana de Enfermedades Infecciosas (IDSA, por sus siglas en inglés) define al grupo de bacterias incluidas en el término ESKAPE: Enterococcus faecium resistente a vancomicina (ERV), Staphylococcus aureus resistente a meticilina (SARM), Klebsiella pneumoniae productora de betalactámasas de espectro extendido (BLEEs), Acinetobacter baumannii, Pseudomonas aeruginosa y especies de Enterobacter spp, como patógenos de alta prioridad, por representar problemas clínicos o 
de salud pública relevante, además de ser muy limitadas las alternativas terapéuticas en estos casos.4 Todas estas especies poseen una amplia variabilidad de genes de resistencia a diferentes clases de antibióticos con un gran potencial de transferencia horizontal entre ellas.

Tabla 1. Clasificación de las betalactámasas

\begin{tabular}{|c|c|c|c|c|c|c|}
\hline \multirow{2}{*}{$\begin{array}{l}\text { Grupo } \\
\text { Bush- } \\
\text { Jacoby }\end{array}$} & \multirow{2}{*}{$\begin{array}{l}\text { Clase } \\
\text { molecular } \\
\text { Subclase }\end{array}$} & \multirow[b]{2}{*}{ Substratos preferidos } & \multicolumn{2}{|c|}{ Inhibidos por } & \multirow[b]{2}{*}{ Principales Características } & \multirow{2}{*}{$\begin{array}{l}\text { Enzimas } \\
\text { representativas }\end{array}$} \\
\hline & & & A. clavulánico & EDTA & & \\
\hline 1 & $\mathrm{C}$ & Cefalosporinas & No & No & $\begin{array}{l}\text { Mejor hidrólisis de cefalosporinas } \\
\text { que de bencilpenicilina }\end{array}$ & $\begin{array}{l}\text { AmpC, P99, ACT- } \\
\text { 1, CYM-2, FOX-1, } \\
\text { MIR-1 }\end{array}$ \\
\hline $1 \mathrm{e}$ & $\mathrm{C}$ & Cefalosporinas & No & No & $\begin{array}{l}\text { Hidrólisis incrementada hacia } \\
\text { ceftazidima y otros oximino-beta- } \\
\text { lactámicos }\end{array}$ & GC1, CMY-37 \\
\hline $2 \mathbf{b}$ & A & $\begin{array}{l}\text { Penicilinas, cefalos- } \\
\text { porinas }\end{array}$ & $\mathrm{Si}$ & No & $\begin{array}{l}\text { Hidrólisis similar de bencilpeni- } \\
\text { cilinas y de cefalosporinas }\end{array}$ & $\begin{array}{l}\text { TEM-1, TEM-2, } \\
\text { SHV-1 }\end{array}$ \\
\hline 2 be & A & $\begin{array}{l}\text { Cefalosporinas de } \\
\text { espectro extendido y } \\
\text { monobactámicos }\end{array}$ & $\mathrm{Si}$ & No & $\begin{array}{l}\text { Hidrólisis incrementada hacia } \\
\text { cefatazidima y otros oximino-beta- } \\
\text { lactámicos } \\
\text { ceftazidima } i ?, \text { ceftriaxona, ce- } \\
\text { fepime) }\end{array}$ & $\begin{array}{l}\text { TEM-3, SHV-2, } \\
\text { CTX-M-15, PER- } \\
\text { 1, VEB-1 }\end{array}$ \\
\hline $2 \mathrm{br}$ & A & Penicilinas & No & No & $\begin{array}{l}\text { Resistencia a ácido clavulánico, } \\
\text { sulbactam y tazobactam }\end{array}$ & TEM-30, SHV-10 \\
\hline 2ber & A & $\begin{array}{l}\text { Cefalosporinas de } \\
\text { espectro extendido y } \\
\text { monobactámicos }\end{array}$ & No & No & $\begin{array}{l}\begin{array}{l}\text { Hidrólisis incrementada } \\
\text { oximino-beta-lactámicos } \\
\text { binados con resistencia } \\
\text { sulbactam y tazobactam }\end{array} \\
\text { com- }\end{array}$ & TEM-50 \\
\hline 2c & A & Carbenicilinas & $\mathrm{Si}$ & No & $\begin{array}{l}\text { Hidrólisis incrementada de la } \\
\text { carbenicilina }\end{array}$ & PSE-1, CARB-3 \\
\hline 2ce & & $\begin{array}{l}\text { Carbenicilinas, ce- } \\
\text { fepime }\end{array}$ & $\mathrm{Si}$ & No & $\begin{array}{l}\text { Hidrólisis incrementada de la } \\
\text { carbenicilina, cefepime y cefpi- } \\
\text { rome }\end{array}$ & RTG-4 \\
\hline 2d & $\mathrm{D}$ & Cloxacilina & Variable & No & $\begin{array}{l}\text { Hidrólisis incrementada de la } \\
\text { cloxacilina o de la oxacilina }\end{array}$ & OXA-1, OXA-10 \\
\hline 2de & $\mathrm{D}$ & $\begin{array}{l}\text { Cefalosporinas de } \\
\text { espectro extendido }\end{array}$ & Variable & No & $\begin{array}{l}\text { Hidrólisis de cloxacilina o oxacilina } \\
\text { y oximino-beta-lactámicos }\end{array}$ & OXA-11, 0XA-15 \\
\hline $2 \mathrm{df}$ & $\mathrm{D}$ & Carbapenems & Variable & No & $\begin{array}{l}\text { Hidrólisis de cloxacilina o oxacilina } \\
\text { y carbapenems }\end{array}$ & OXA-23, OXA-48 \\
\hline $2 e$ & A & $\begin{array}{l}\text { Cefalosporinas de } \\
\text { espectro extendido }\end{array}$ & $\mathrm{Si}$ & No & $\begin{array}{l}\text { Hidrólisis de cefalosporinas. } \\
\text { Inhibido por ácido clavulánico } \\
\text { pero no por aztreonam }\end{array}$ & CepA \\
\hline $2 f$ & A & Carbapenems & Variable & No & $\begin{array}{l}\text { Hidrólisis incrementada de car- } \\
\text { bapenems, oximino-beta-lac- } \\
\text { támicos, cefamicinas }\end{array}$ & $\begin{array}{l}\text { KPC-2, IMI-1, } \\
\text { SME-1 }\end{array}$ \\
\hline $3 a$ & B (B1) & Carbapenems & No & $\mathrm{Si}$ & $\begin{array}{l}\text { Hidrólisis de espectro extendido } \\
\text { incluyendo carbapenems pero no } \\
\text { monobactams }\end{array}$ & $\begin{array}{l}\text { IMP-1, VIM-1, } \\
\text { CrA, IND-1 }\end{array}$ \\
\hline & B (B3) & & & & & $\begin{array}{l}\text { L1, CAU-1, GOB- } \\
\text { 1, FEZ-1 }\end{array}$ \\
\hline $3 \mathbf{b}$ & B (B2) & Carbapenems & No & $\mathrm{Si}$ & $\begin{array}{l}\text { Hidrólisis preferente de car- } \\
\text { bapenems }\end{array}$ & CphA, Sfh-1 \\
\hline
\end{tabular}

Fuente: Mecanismos moleculares de resistencia antibiótica en Escherichia coli asociadas a diarrea.27 


\section{Genes de resistencia de betalactamasas de espectro extendido}

Los betalactámicos son antibióticos de acción bactericida que actúan sobre la fase final de síntesis del peptidoglicano. Actúan como sustratos competitivos de distintas enzimas participantes en la síntesis de pared, esencialmente de las transpeptidasas denominadas proteínas fijadoras de penicilina (PBP); ya que presentan una similitud estructural con el extremo D-alanina-D-alanina del pentapéptido que enlaza las cadenas de $\mathrm{N}$ acetilmurámico y $\mathrm{N}$-acetilglucosamina del peptidoglicano.27 Las betalactámasas generalmente son clasificadas de acuerdo a dos esquemas el de Ambler y el de Bush-JacobyMadeiros (Tabla 1).

La clasificación de Ambler posee cuatro clases A, B, C, D, y está basada en la similitud u homología de los aminoácidos y no tiene en cuenta las características fenotípicas. En esta clasificación la clase B son metalobetalactamasas y C - D serino betalactámasas. La clasificación de Bush-JacobyMadeiros se basa en la similitud funcional y la características de inhibición o no por el ácido clavulánico.28

Esta clasificación muestra las enzimas y el sustrato que relaciona los antibióticos, en algunas especies bacterianas se expresan varias enzimas lo que dificulta el tratamiento de numerosas infecciones por presentar resistencia a la mayoría de los betalactámicos, y altas tasas de resistencia a antimicrobianos de otras familias. El perfil de multirresistencia que expresan estas cepas productoras de BLEE, ocasionan un problema terapéutico importante tanto en el ámbito hospitalario como en el comunitario.29-31

Las BLEE han emergido como el principal problema en pacientes hospitalizados, así como en pacientes en la comunidad; siendo los principales responsables de una variedad de infecciones tales como infecciones del tracto urinario (ITU), septicemia, neumonía adquirida en el hospital, abscesos intra-abdominales, abscesos del cerebro e infecciones relacionadas con dispositivos médicos.32 En los últimos cinco años se ha evidenciado en todo el mundo un considerable aumento de aislamientos de enterobacterias productoras de BLEE con tasas tan altas que llegan hasta 55 y $79 \%$ en China e India, respectivamente. 33

En América Latina, la resistencia de las enterobacterias se ha incrementado desde 1990 por la difusión de las BLEE, algunas de las cuales se originaron en el continente y pueden ser responsables de tasas de resistencia hasta de 40\% en los aislamientos de Klebsiella pneumoniae.11 En Colombia el reporte de la resistencia se inició a finales de los años 90 siendo esta la primera alarma sobre el aumento de la resistencia bacteriana.5 A partir del año 2001 empezó a reportarse de forma sistemática la resistencia bacteriana en hospitales colombianos gracias a la adaptación de sistemas de vigilancia implementados por diversos grupos de investigación como GREBO y GERMEN; y a la adopción de dichos sistemas de vigilancia por parte de los entes gubernamentales (SIVIBAC en Bogotá).5

Las BLEE surgen principalmente debido a mutaciones en betalactámasas codificadas por el gen bla SHV, bla TEM, y bla CTX-M. Como resultado, se han identificado cerca de 300 variantes naturales de genes BLEE's, tales como tipo TEM, tipo SHV, tipo CTX-M, tipo OXA y de otros tipo BLEEs.34-37 Los genes de las BLEE son transmitidos por plásmidos y a menudo se encuentran en los transposones e integrones, facilitando su movilización con otro mecanismo de resistencia. Los plásmidos que determinan las BLEE contienen, con frecuencia, otros genes de resistencia para distintos antimicrobianos, como aminoglucósidos, tetraciclinas y cotrimoxazol.38

Los genes que codifican las BLEE pueden ser fácilmente transferidos horizontalmente entre e intra especies, presentándose la transferencia más frecuente de los genes TEM, SHV y CTX-M entre otros.39,40 Las BLEE se originaron y derivan en su mayoría de las betalactamasas clásicas TEM y SHV las cuales surgen a partir de una serie de mutaciones puntuales que alteran su centro activo, como respuesta a la presión selectiva ejercida por el amplio uso de las cefalosporinas de tercera generación, permitiéndoles modificar su 
perfil de sustrato, mejorando su capacidad de hidrólisis frente a los betalactámicos. 41

\section{Gen bla TEM}

La enzima TEM-1 es la betalactámasas que se ha descrito con mayor frecuencia en Gram negativos y está codificada por el gen blaTEM-1. Esta enzima confiere resistencia a ampicilina, penicilina y cefalosporinas de primera generación como cefalotina.42 La enzima TEM fue nombrada del paciente del que procedía, Temoneira, y fue identificada por primera vez en Escherichia coli en Grecia. Este tipo de BLEE se ha expandido rápidamente y es ahora uno de los tipos de BLEE más dominantes en muchos países, el número de mutantes ha alcanzado hasta TEM-167.43,18

En 1969 fueron descritas las primeras enzimas de TEM en Pseudomonas aeruginosa y de 1973 a 1975 se encontraron en Haemophilus influenzae, Vibrio cholerae y Neisseria gonorrhoeae; luego en 1983 se detectaron en Alemania los primeros aislamientos de Klebsiella pneumoniae y Escherichia coli resistentes a cefalosporinas de tercera generación, de los cuales se demostró que la resistencia era debida a la producción de una betalactámasas plasmídica transferible, denominándose BLEE. Estas enzimas derivan de mutaciones concretas en los genes que codifican las betalactamasas clásicas (TEM-1, TEM-2 y SHV-1), a la primera de estas betalactamasas descubiertas, se les denominó TEM-3 por ser una variante de la TEM-2; desde entonces, se han descrito muchos polimorfismos en este grupo.44 De igual forma, los cambios originados en su secuencia de aminoácidos, han dado lugar a una gran variedad de enzimas (de TEM-3 a TEM-29 y de SHV-2 a SHV-7).45-47

\section{Gen bla SHV}

En la década de los ochenta se inició el empleo clínico de las llamadas cefalosporinas de tercera generación, también conocidas como oximinocefalosporinas. Sin embargo, en 1983 se descubrió en Alemania la primera enzima capaz de hidrolizar las cefalosporinas de más amplio espectro (SHV-2), y se han descrito diferentes mutaciones que se originaron de la SHV-1 a SHV63 (44) hasta SHV-114.48,49,18 La enzima SHV se denomina sulfhidrilo variable y se asocia con
Klebsiella pneumoniae. Está codificada por el gen bla SHV-1, y confiere resistencia a las penicilinas y a las cefalosporinas de primera generación; encontrándose en cepas de Klebsiella pneumoniae, aunque también se ha descrito en Escherichia coli.42

\section{Gen bla CTX-M}

La betalactamasa codificada por el gen bla CTX-M15 fue reportado por primera vez en India en 1990, y en Colombia en el año 2004. 50,51Las CTXM se caracterizan por su alta capacidad hidrolítica sobre cefalosporinas en especial sobre la cefotaxima y a la ceftriaxona y poca capacidad de hidrolizar la ceftazidima y cefepime.32 Este genotipo es un buen ejemplo de betalactamasas cromosómicas, encontradas normalmente en especies de "Kluyvera ascorbata", un grupo relativamente raro de patógenos comensales reportado en 1989 por primera vez, caracterizado por hidrolizar mejor a cefalosporinas como cefuroxima, cefotaxima y cefepima que ceftazidima.41 Estas enzimas no están muy relacionadas con las TEM o SHV, ya que solo muestran un $40 \%$ de identidad con las mismas. Se conocen más de 80 tipos de CTX-M, de las cuales algunas son más activas contra ceftazidima que contra cefotaxima. Además, se han encontrado en cepas de Salmonella enterica serovar typhimurium, Escherichi coli, pero también han sido descritas en otras especies de Enterobacteriaceae; siendo predominante los tipos CTX-M-14, CTX-M- 3, y CTX-M-2.41

\section{Gen Amp- C}

Las betalactamasas $A m p \mathrm{C}$ son enzimas cromosomales (gen $A m p C$ ) de expresión inducible, con actividad contra las penicilinas, pero tienen más actividad contra las cefalosporinas y pueden hidrolizar las cefamicinas, (cefoxitina y cefotetan), oximinocefalosporinas (ceftazidima, cefotaxime y ceftriaxona), monobactamicos (aztreonam); y aminopenicilinas combinadas con inhibidores de betalactamasas (amoxicilina-ácido clavulánico,ampicilina-sulbactam). 10,52 Este gen pertenece a la clase $\mathrm{C}$ de la clasificación estructural de Ambler y al grupo I de la clasificación funcional de Busch. La primera enzima bacteriana reportada que destruía la 
penicilina fue la $A m p C$ de la Escherichia coli, aunque esta no fue nombrada sino hasta 1940 por investigadores suizos. 53

Ciertas enterobacterias poseen de manera natural betalactámasas $A m p \mathrm{C}$ tales como: Enterobacter spp, Providencia spp, Morganella morganii, Serratia marcescens, Citrobacter freundii y Hafnia alvei; así como en bacilos Gram negativos no fermentadores de lactosa como Pseudomonas aeruginosa.52 Las AmpC de estos microorganismos son de naturaleza cromosómica, mientras que las betalactámasas AmpC en Escherichia coli son también cromosómicas no inducibles pero su expresión generalmente es baja.53

En la mayoría de enterobacterias que expresan el gen $A m p C$ se encuentran en el cromosoma bacteriano y su expresión es de bajo nivel e inducible como respuesta a la exposición a ciertos betalactámicos está regulada por un operon amp que requiere la presencia de betalactámicos con al menos cinco genes $(a m p C, a m p R, a m p D, a m p G$, $a m p E$ ) y está íntimamente relacionado con el reciclaje del peptidoglicano. 54

El mecanismo de inducción de la betalactámasa $A m p C$ depende del gen $a m p R$, que actúa como activador durante el proceso de inducción y como represor en condiciones normales.55 Los genes ampC y $a m p E$ codifican la síntesis de proteínas de membrana y $a m p D$ da lugar a una proteína soluble que se libera en el citoplasma; mientras AmpG actúa como una permeasa y facilita la entrada en el citoplasma de los productos de degradación del peptidoglicano. AmpD metaboliza los productos de degradación que se están produciendo en el citoplasma lo cual favorece el reciclaje de la pared, ya que los metabolitos resultantes se reutilizan en la formación del propio peptidoglicano. 54

\section{Genes de carbapenémicos}

La producción de betalactamasas tipo carbapenemasas es un mecanismo de resistencia de gran importancia en bacilos Gram negativos, observándose que los aislamientos productores en general resultan resistentes no sólo a imipenem y meropenem, sino también a otros antibióticos betalactámicos que se utilizan para el tratamiento antimicrobiano. Estas enzimas, codificadas por genes que en su mayoría están localizados en elementos genéticos tales como los integrones o insertados en elementos móviles como transposones y plásmidos, se han extendido rápidamente entre los agentes patógenos de importancia clínica.56

Las carbapenemasas son betalactámasas que, además de degradar carbapenémicos, hidrolizan prácticamente todos los betalactámicos. Según su naturaleza, se pueden clasificar en cuatro clases: A, B, C y D; las clases A, C y D incluyen betalactámasas con serina en su sitio activo, mientras que las betalactámasas de clase B, corresponden a metalo-enzimas dependientes de zinc.7 Esta resistencia puede estar determinada por la pérdida de la porina $\operatorname{OprD}$ combinada en represión cromosomal gel gen $a m p C$ o por sobreexpresión del mecanismo de expulsión activa del antibiótico.58,59

La clasificación de las betalactamasas se basa tradicionalmente en sus características funcionales o estructura primaria; teniendo en cuenta la secuencia de proteínas se establecen cuatro grupos, A, B, C, y D, clasificación en la que se encuentran las carbapenemasas, enzimas capaces de hidrolizar la mayor parte de betalactámicos, incluidos los carbapenémicos; las de clase B o metalo-betalactamasas, por ejemplo, VIM (Verona Integron-encoded Metallo-

betalactamase) o IMP (imipenemasa), que no presentan actividad frente a aztreonam y cuya acción es inhibida con EDTA (ethylene-diaminetetra-acetic acid); las de clase $D$, que tienen actividad frente a oxacilinas, siendo la OXA-48 la más frecuentemente reportada.

Por último, las de clase A, que suelen ser sensibles a la acción del ácido clavulánico y presentan una menor actividad frente a meropenem que a imipenem, y de las cuales la KPC (Klebsiella pneumoniae carbapenemase) las cuales son las más ampliamente diseminada en todo el mundo en sus variantes KPC-2 y KPC-3 (Tabla 2).60,61 
Tabla 2. Clasificación de las carbapenemasas

\begin{tabular}{|c|c|c|c|c|c|c|}
\hline \multirow{2}{*}{$\begin{array}{l}\text { Clase } \\
\text { molecular }\end{array}$} & \multirow[t]{2}{*}{ Enzimas } & \multicolumn{2}{|c|}{ Inhibición por } & \multirow[t]{2}{*}{ ATM } & \multirow[t]{2}{*}{ Microorganismo } & \multirow{2}{*}{$\begin{array}{l}\text { Localización } \\
\text { genética }\end{array}$} \\
\hline & & CLA & EDTA & & & \\
\hline \multirow[t]{3}{*}{$\mathrm{A}(2 \mathrm{~F})$} & Sme, IMI, NmcA & +- & - & $\mathrm{R}$ & $\begin{array}{l}\text { Serratia marcescens } \\
\text { Enterobacter cloacae }\end{array}$ & Crom \\
\hline & KPC & + & - & $\mathrm{R}$ & Enterobacterias & PI \\
\hline & GES & + & - & $\mathrm{R}$ & Pseudomonas aeruginosa & PI \\
\hline \multirow[t]{2}{*}{ B (3) } & L1, CcrA, CpHa, Bcll & - & + & $\mathrm{S} / \mathrm{R}$ & $\begin{array}{l}\text { Stenotrophomonas maltophilia } \\
\text { Bacteroides fragilis } \\
\text { Aeromonas hydrophilia } \\
\text { Bacillus cereus }\end{array}$ & Crom \\
\hline & IMP,SPM,SIM & - & + & $S$ & $\begin{array}{l}\text { Enterobacterias } \\
\text { Pseudomonas spp } \\
\text { BGNNF }\end{array}$ & PI(Crom) \\
\hline$D(2 d f)$ & OXA (OXA-48) & +- & - & S & $\begin{array}{l}\text { Acinetobacter baumannii } \\
\text { Pseudomonas aeruginosa } \\
\text { Enterobacterias }\end{array}$ & Crom, PI \\
\hline
\end{tabular}

CLA: ácido clavulánico. ATM: Aztreonam. Crom: codificación cromosómica. PI: plasmidica.56

Los carbapenemes son a la fecha los betalactámicos con el espectro de actividad más amplio, por esta razón, estas moléculas son de primera importancia en el tratamiento de infecciones intrahospitalarias, principalmente de aquellas causadas por enterobacterias productoras de betalactamasas de espectro extendido (BLEE). El mecanismo más importante de resistencia a carbapenémicos en enterobacterias es la producción de carbapenemasas, aunque dicha resistencia también puede deberse a la combinación de betalactamasas tipo $A m p C$ o, en menor medida, de espectro extendido, combinadas con disminución de la permeabilidad de la membrana externa.62

La primera cepa de Klebsiella pneumoniae productora de KPC fue aislada e identificada en el estado norteamericano de Carolina del Norte en 1996 y en 2005, Colombia fue el primer país de América Latina que reportó la presencia de infecciones por esta bacteria,seguida por Brasil en 2006, Argentina en 2008, Venezuela en 2011 y Chile en $2012 \cdot 63-68,39$

Las metalobetalactamasas (MBL) son la clase más diversa de carbapenemasas que representan una importante amenaza clínica, estas pertenecen a la clase $B$ según la clasificación de Ambler y presentan actividad hidrolítica frente a los antibióticos betalactámicos (excepto frente a los monobactámicos); son inhibibles por agentes quelantes de cationes divalentes como EDTA y mercaptoacetato de sodio (MAS), y escapan de la acción de todos los inhibidores de betalactamasas de uso clínico, como el ácido clavulánico y la sulbactam. En cuanto a los genes de estos, pueden encontrarse en el cromosoma bacteriano o en elementos genéticos móviles; especialmente en integrones asociados a plásmidos conjugativos; dentro de las principales sobresale las de tipo IMP, VIM y NDM.69 Dentro de las MBL transferibles, se distinguen nueve grupos: IMP, VIM, SPM, GIM, AIM, NDM, SIM, DIM y KHM. Las primeras seis han sido encontradas en Pseudomonas aeruginosa, siendo las IMP y VIM las más diseminadas en el mundo.70

\section{Gen bla NDM-1}

La metalobetalactamasa Nueva Delhi (bla NDM1), fue una betalactamasas descrita en el 2008 que presenta resistencia a penicilinas, cefalosporinas y sus derivados. Los primeros reportes demostraron que este nuevo mecanismo de resistencia, aunado a otros mecanismos que poseen las bacterias Gram negativas, ocasiona un incremento en la morbilidad y la mortalidad en pacientes hospitalizados que adquieren una infección.50,71,72

\section{Gen bla KPC}

La enzima se encuentra codificada por el gen bla $\mathrm{KPC}$, el cual generalmente se localiza en plásmidos, y le confiere la capacidad de compartir esta información genética con otras especies y familias de bacterias; se encuentra localizado en 
un elemento genético móvil, facilitando su diseminación "clonal" y geográfica.55,60 Esta enzima tiene la capacidad de hidrolizar eficientemente penicilinas, cefalosporinas, monobactámicos y, menos eficientemente, las cefamicinas y los carbapenem.61 Fue detectada por primera vez en Klebsiella pneumoniae en 2001 en Carolina del Norte causando múltiples epidemias dentro y fuera de Estados Unidos. En Colombia, la primera detección de aislamientos productores de KPC se reportó en el año 2006 en la ciudad de Medellín, presente en aislamientos de K. pneumoniae y luego, en 2007, fue encontrada en 3 aislamientos clínicos de $P$. aeruginosa en la misma ciudad y desde entonces, ha sido reportada en diferentes ciudades.62,64,73

\section{Gen bla VIM}

Las enzimas VIM se identificaron por primera vez en el año de 1996 en Francia en cepas de Pseudomona aeruginosa y poseen especificidad para un amplio espectro de sustratos, con alta afinidad por las cefalosporinas y los carbapenem.59,74 Los genes bla IMP se encuentran con frecuencia alojados en integrones de clase 1 que se localizan en transposones, y estos constituye un aparato genético de alta capacidad de movilización, que facilita la diseminación horizontal. Generalmente los genes bla IMP coexisten con otros genes de resistencia en plásmidos los cuales pueden poseer además otros genes de resistencia a antibióticos no betalactámicos.69 En los últimos años se ha identificado otros tipos de gen VIM como VIM-3, VIM-4, VIM -5, VIM-6, VIM-7, VIM-8, VIM-11,VIM13, VIM-15 y VIM-16 los cuales difieren en la cantidad de aminoácidos y la susceptibilidad hacia algunos antibióticos debido a que presentan fenotipos de resistencia diferentes entre cada tipo de VIM.59,74

\section{Gen bla IMP}

El gen IMP-1 se identificó por primera vez en Japón en el año 1991 en cepas de Serratia marcescens y Pseudomonas aeruginosa resistentes a Carbapenémicos, el gen responsable estaba localizado en un plásmido de gran tamaño (36 Kb) y formaba parte de un cassette incluido en un integrón de clase 1 (In31). Desde entonces se han comunicado diversas variantes del enzima IMP en diferentes países: IMP-7, IMP-9, IMP-13, IMP-16, IMP-18 (74).74 Posteriormente, se han descrito nuevos IMP como VIM-1 en Italia, VIM-2 en Francia, SPM-1 en Brasil y GIM -1 en Alemania.59

\section{Gen bla IMI}

La expresión del gen bla IMI está regulada por la proteína reguladora de la transcripción LysR, que está codificada por el gen blaIMI-R, adyacente a bla IMI. Los primeros reportes fueron descubiertos en Enterobacter cloacae en Norteamérica en 1996 (75) y se propagó en todo el mundo después del año 2000.75 El gen blaIMI-1 se encuentra en el cromosoma bacteriano; sin embargo se originó a partir de una mutación puntual de blaIMI-2, fue identificado posteriormente codificado en un plásmido en cepas de Enterobacter asburiae recuperado en EE.UU.62

\section{Gen OXA}

Las oxacilinasas (enzimas tipo OXA) son enzimas de clase D que pertenecen al grupo funcional $2 \mathrm{~d} y$ fueron identificadas por primera vez en una cepa de Klebsiella pneumoniae en 2004.76 Son un amplio grupo de enzimas con un espectro hidrolítico muy desigual que generalmente están codificadas por genes integrados en plásmidos o integrones, el cual tiene como característica no se inhibirse con ácido clavulánico, sulbactam o tazobactam, con la excepción de OXA-18, lo que dificulta su detección en el laboratorio.74

En los últimos años, se han identificado seis nuevas enzimas tipo-OXA aisladas de cepas con resistencia a carbapenemes, la enzima OXA-24 se encontró en cepas de España(77) y representan el segundo subgrupo de estas enzimas con un $60 \%$ de identidad con la enzima OXA-23, se conocen otro tipo de enzimas entre las que se encuentran relacionadas a: OXA-25, OXA-26 y OXA-40 presentes en cepas de España, Bélgica y Portugal $(35,78)$ y dos variantes de OXA-23, OXA-27 y OXA-49 que se encontraron en cepas aisladas de Singapore, China (79) y Brasil.35,77-80

En Argentina se identificó una nueva enzima, denominada OXA-51 que comparte un $63 \%$ de identidad con las enzimas de los subgrupos 1 y 2 y posteriormente se identificaron siete enzimas 
en diferentes partes del mundo que comparten el 98-99\% de identidad con OXA-51.81,82

\section{Conclusiones}

La identificación y confirmación de las betalactamasas de espectro extendido y las de tipo carbapenemasas son los mecanismos idóneos para orientar adecuadamente el tratamiento; además de disminuir los fracasos terapéuticos y complicaciones clínicas de las personas infectadas por estos microorganismos. Se ha demostrado que este tipo de bacterias tienen diferentes mecanismos por los cuales adquieren mutaciones puntuales a nivel cromosómico o transferencia horizontal de material genético entre especies relacionadas o no, facilitada por algunos elementos móviles los cuales tienen la capacidad de diseminarse. Dicha característica, ha generado un incremento en la resistencia a antibióticos en todo el mundo de manera alarmante.

El control de la resistencia antimicrobiana, desde el punto de vista de la epidemiología molecular, forma parte transcendental del control de la vigilancia antibiótica tal como lo recomienda la Organización Mundial de la Salud; pues representa el futuro de la vigilancia de resistencia, ya que se origina debido al uso indiscriminado de los antibióticos. Como consecuencia, se presentan fenotipos de resistencia cruzada hacia otros antimicrobianos de la misma clase o con el mismo mecanismo de acción e incluso de otras familias, por lo que se convierte en una herramienta para estudiar sus mecanismos genéticos y ejercer un control. A pesar de dicho control, se hace necesario formular proyectos de investigación que identifique los aspectos medioambientales y genéticos más importantes en la generación de fenotipos multiresistentes en varias regiones de Colombia.

\section{Referencias}

1. Tenover FC. Mechanisms of antimicrobial resistance in bacteria. The American journal of medicine. 2006;119(6):S3-S10.

2. Bassett EJ, Keith MS, Armelagos GJ, Martin DL, Villanueva AR. Tetracycline-labeled human bone from ancient Sudanese Nubia (AD 350). Science. 1980;209(4464):1532-4.

3. Vives-Soto M, Difabio M. Tratamiento de las infecciones por enterobacterias. Medicine-Programa de Formación Médica Continuada Acreditado. 2010;10(51):3432-9.

4. García Castellanos T, Castillo Marshal A, Salazar Rodríguez D. Mecanismos de resistencia a betalactámicos en bacterias gramnegativas. Revista Cubana de Salud Pública. 2014;40(1):129-35.

5. González L, Cortés JA. Revisión sistemática de la farmacorresistencia en enterobacterias de aislamientos hospitalarios en Colombia. Biomédica. 2014;34(2):18097.

6. Pérez N, Pavas N, Rodríguez EI. Resistencia a los antibióticos en Escherichia coli con beta-lactamasas de espectro extendido en un hospital de la Orinoquia colombiana. Infectio. 2011;15(3):147-54.

7. Gaitán SL, Espinal PA. Caracterización molecular de Escherichia coli y Klebsiella pneumoniae productores de ß-lactamasas de espectro extendido en hospitales de la Región Caribe, Colombia. Revista chilena de infectología. 2009;26(3):239-46.

8. Villalobos AP, Barrero LI, Rivera SM, Ovalle MV, Valera D. Vigilancia de infecciones asociadas a la atención en salud, resistencia bacteriana y consumo de antibióticos en hospitales de alta complejidad, Colombia, 2011. Biomédica. 2014;34:67-80.

9. Bhattacharya S. Early diagnosis of resistant pathogens: how can it improve antimicrobial treatment? Virulence. 2013;4(2):172-84.

10. Hernández-Gómez C, Blanco VM, Motoa G, Correa A, Maya JJ, de la Cadena E, et al. Evolución de la resistencia antimicrobiana en bacilos Gram negativos en unidades de cuidados intensivos en Colombia. Biomédica. 2014;34(Supl 1):91-100.

11. Casellas JM. Antibacterial drug resistance in Latin America: consequences for infectious disease control. Revista Panamericana de Salud Pública. 2011;30(6):519-28.

12. Organization WH. Containing antimicrobial resistance: review of the literature and report of a WHO Workshop on the Development of a Global Strategy for the Containment of Antimicrobial Resistance, Geneva, Switzerland, 4-5 February 1999. 1999.

13. Oggioni MR, Dowson CG, Smith JM, Provvedi R, Pozzi G. The Tetracycline Resistance Gene $<$ i $>$ tet $</ \mathrm{i}>(\mathrm{M})$ Exhibits Mosaic Structure. Plasmid. 1996;35(3):156-63.

14. Jaramillo V, León E. Vigilancia epidemiológica de infecciones intrahospitalarias. Hospital de Caldas 19891993. 2014.

15. Donoso NAA. Resistencia Bacteriana en Unidad de Cuidados Intensivos Adultos de la Clínica Medilaser, Neiva-Colombia, entre enero y diciembre de 2008. Revista Facultad de Salud-RFS. 2015;1(2):31-7.

16. Barrero LI, Castillo JS, Leal AL, Sánchez R, Cortés JA, Álvarez CA, et al. Impacto económico de la resistencia a la meticilina en pacientes con bacteriemia por Staphylococcus aureus en hospitales de Bogotá. Biomédica. 2014;34(3):345-53.

17. Echeverri-Toro LM, Rueda ZV, Maya W, Agudelo Y, Ospina S. Klebsiella pneumoniae multi-resistente, 
factores predisponentes y mortalidad asociada en un hospital universitario en Colombia. Revista chilena de infectología. 2012;29(2):175-82.

18. Garza-Ramos U, Silva-Sánchez J, Martínez-Romero E. Genetics and genomics for the study of bacterial resistance. Salud Pública de México. 2009;51:s439-s46.

19. Cabrera CE, Gómez RF, Zúñiga AE. La resistencia de bacterias a antibióticos, antisépticos y desinfectantes una manifestación de los mecanismos de supervivencia y adaptación. Colombia médica. 2007;38(2):149-58.

20. Tellevik MG, Sollid JE, Blomberg B, Jureen R, Urassa WK, Langeland N. Extended-spectrum $\beta$-lactamase-type SHV-12-producing Enterobacteriaceae causing septicemia in Tanzanian children: vectors for horizontal transfer of antimicrobial resistance. Diagnostic microbiology and infectious disease. 2007;59(3):351-4.

21. Frost LS, Leplae R, Summers AO, Toussaint A. Mobile genetic elements: the agents of open source evolution. Nature Reviews Microbiology. 2005;3(9):722-32.

22. Bissonnette L, Roy PH. Characterization of In0 of Pseudomonas aeruginosa plasmid pVS1, an ancestor of integrons of multiresistance plasmids and transposons of gram-negative bacteria. Journal of bacteriology. 1992;174(4):1248-57.

23. Gonzalez G, Sossa K, Bello H, Dominguez M, Mella S, Zemelman R. Presence of integrons in isolates of different biotypes of Acinetobacter baumannii from Chilean hospitals. FEMS microbiology letters. 1998;161(1):125-8.

24. Paulsen I, Littlejohn T, Rådström P, Sundström L, Sköld 0 , Swedberg G, et al. The 3'conserved segment of integrons contains a gene associated with multidrug resistance to antiseptics and disinfectants. Antimicrobial Agents and Chemotherapy. 1993;37(4):761-8.

25. Bennett PM. Integrons and gene cassettes: a genetic construction kit for bacteria. Journal of Antimicrobial Chemotherapy. 1999;43(1):1-4.

26. González R G, Mella M S, Zemelman Z R, Bello T H, Domínguez Y M. Integrones y cassettes genéticos de resistencia: estructura y rol frente a los antibacterianos. Revista médica de Chile. 2004;132:619-26.

27. Mosquito S, Ruiz J, Bauer JL, Ochoa TJ. Mecanismos moleculares de resistencia antibiótica en Escherichia coli asociadas a diarrea. Rev Peru Med Exp Salud Publica. 2011;28(4):648-56.

28. Máttar S, Martínez P. Emergencia de la resistencia antibiótica debida a las $\beta$-lactamasas de espectro extendido (BLEE): detección, impacto clínico y epidemiología. Infectio. 2007;11(1):23-35.

29. Morejón García M. Betalactamasas de espectro extendido. Revista Cubana de Medicina. 2013;52(4):272-80.

30. Amado NY, Fajardo HD, Ramírez RY, González GI. Prevalencia de betalactamasas de espectro extendido en bacilos gramnegativos de una institución de salud de Tunja (Colombia) en el año 2013. Salud \& Sociedad. 2015;1(2).

31. Molina LC, Barragan IT, Sánchez MT. Comportamiento epidemiológico y clínico de las infecciones por E. Coli productora de betalactamasa de espectro extendido
(BLEE) en la Clínica Universitaria San Juan de Dios de enero 2010 a diciembre de 2011. ESPIGA CIENTÍFICA. 2014;9(2).

32. Alarcón NC, Gonzalez JFS, Sarabia RLO, Sánchez JS, Rosas MR. Caracterización de $\beta$-lactamasas de espectro extendido producidas por Escherichia coli de infecciones del tracto urinario adquiridas en la comunidad de Chilpancingo, Guerrero, México. 2014.

33. Sevgi DY, Gunduz A, Sahin AM, Derin O, Konuklar AS, Oncul A, et al. Ertapenem for the treatment of complicated urinary tract infections caused by extended-spectrum $\beta$-lactamase-producing bacteria: a case series report. Disease and Molecular Medicine. 2014;2(1):7-11.

34. Ahmed OI, El-Hady SA, Ahmed TM, Ahmed IZ. Detection of bla SHV and bla CTX-M genes in ESBL producing Klebsiella pneumoniae isolated from Egyptian patients with suspected nosocomial infections. Egyptian Journal of Medical Human Genetics. 2013;14(3):277-83.

35. Afzal-Shah $M$, Woodford $N$, Livermore DM. Characterization of OXA-25, OXA-26, and OXA-27, molecular class D $\beta$-lactamases associated with carbapenem resistance in clinical isolates of Acinetobacter baumannii. Antimicrobial agents and chemotherapy. 2001;45(2):583-8.

36. Cantón R, González-Alba JM, Galán JC. CTX-M enzymes: origin and diffusion. Frontiers in microbiology. 2012;3.

37. Yu Y, Ji S, Chen Y, Zhou W, Wei Z, Li L, et al. Resistance of strains producing extended-spectrum beta-lactamases and genotype distribution in China. The Journal of infection. 2007;54(1):53-7.

38. Rodríguez-Avial C, Rodríguez-Avial I, Hernández E, Picazo JJ. Aumento significativo de la resistencia a fosfomicina en cepas de Escherichia coli productoras de $\beta$-lactamasas de espectro extendido (BLEE) aisladas de urocultivos (2005-2009-2011). Rev Esp Quimioter. 2013;26:43-6.

39. Velásquez J, Hernández R, Pamo O, Candiotti M, Pinedo Y, Sacsaquispe R, et al. Klebsiella pneumoniae resistente a los carbapenemes. Primer caso de carbapenemasa tipo KPC en Perú. Rev Soc Peru Med Interna. 2013;26(4):193.

40. Guzmán M, Rodríguez E, Antón K, Silva S, Navarro J, Lastra L, et al. Genes blaTEM, blaSHV y blaCTX-M en enterobacterias productoras de $\beta$-lactamasas de espectro extendido aisladas de pacientes con infección intrahospitalaria. Investigación Clínica. 2013;54(3).

41. Arce Z, Nuñez JL, Clavo RF, Valverde DF. Detección del gen CTX-M en cepas de Escherichia coli productoras de B-lactamasas de espectro extendido procedentes del Hospital Regional de Lambayeque; Chiclayo-Perú: Noviembre 2012-Julio 2013. Revista del Cuerpo Médico Hospital Nacional Almanzor Aguinaga Asenjo. 2013;6(4):12-5.

42. Arce Z, Alarcón E, Limo J, Llontop J, Valle J. Detección de genes shv y tem en cepas de Escherichia coli productoras de B-lactamasas de espectro extendido procedentes de dos centros hospitalarios de ChiclayoPerú: enero-agosto 2011. Revista del Cuerpo Médico Hospital Nacional Almanzor Aguinaga Asenjo. 2012;5(3):13-6. 
43. González AC, Nieves B, Solórzano M, Cruz J, Puig J, Moreno M. Caracterización de cepas de Klebsiella pneumoniae productora de $\beta$-lactamasa de espectro extendido aisladas en dos unidades de cuidados intensivos. Revista chilena de infectología. 2013;30(4):374-80.

44. Gobernado M. Betalactamasas de espectro extendido en aumento. Revista Española de Quimioterapia. 2005;18(2):1-3.

45. Araque M, Rivera I. Simultaneous presence of blaTEM and blaSHV genes on a large conjugative plasmid carried by extended-spectrum $\quad \beta$-lactamase-producing Klebsiella pneumoniae. The American journal of the medical sciences. 2004;327(3):118-22.

46. Mena AP, González MC, Pérez MG, Harris B. Caracterización Molecular y Detección de Betalactamasas de Espectro Extendido en Cepas de E. coli y K. pneumoniae Aisladas en las Unidades de Cuidados Intensivos de un Hospital Universitario. Kasmera. 2007;35(2).

47. Perozo A, Castellano M, Ginestre M, Ávila Y. Determinación de Betalactamasas plasmídicas de espectro extendido (ESBL) en cepas de. Escherichia coli.71.

48. García CS, de la Gándara MP, García FJC. Betalactamasas de espectro extendido en enterobacterias distintas de Escherichia coli y Klebsiella. Enfermedades Infecciosas y Microbiología Clínica. 2010;28:12-8.

49. Jiménez A, Alvarado A, Gómez F, Carrero G, Fajardo C. Factores de riesgo asociados al aislamiento de Escherichia coli o Klebsiella pneumoniae productoras de betalactamasas de espectro extendido en un hospital de cuarto nivel en Colombia. Biomédica. 2014;34(Supl 1):16-22.

50. Kumarasamy KK, Toleman MA, Walsh TR, Bagaria J, Butt F, Balakrishnan R, et al. Emergence of a new antibiotic resistance mechanism in India, Pakistan, and the UK: a molecular, biological, and epidemiological study. The Lancet infectious diseases. 2010;10(9):597-602.

51. Pulido IY, Mantilla JR, Valenzuela EM, Reguero MT, Gonzalez EB. Distribution of extended spectrum $\beta$ lactamases-codifying genes in Klebsiella pneumoniae isolates from hospitals of Bogota, DC, Colombia. Biomédica. 2011;31(1):15-20.

52. Rojas M, Del Valle D. Betalactamasas tipo AmpC: generalidades y métodos para detección fenotípica. Rev Soc Venez Microbiol. 2009;29(2):78-83.

53. Flórez Romero A. Factores de riesgo para infección de vías urinarias por enterobacterias productoras de betalactamasas de espectro extendido o AmpC adquiridas en la comunidad. 2013.

54. Seral C, Gude MJ, Castillo FJ. Emergencia de $\beta$-lactamasas AmpC plasmídicas (pAmpC ó cefamicinasas): origen, importancia, detección y alternativas terapéuticas. Rev Esp Quimioter. 2012;25(2):89-99.

55. Pfeifer Y, Cullik A, Witte W. Resistance to cephalosporins and carbapenems in Gram-negative bacterial pathogens. International Journal of Medical Microbiology. 2010;300(6):371-9.
56. Gonzales-Escalante E. Metalo- $\beta$-lactamasas: $¿$ el fin de los $\beta$-lactámicos. Numeración para versión electrónica-07. 2012.

57. de la Lastra V, Rivas LM, Silva F, Ulloa MT, Pinto ME, Vidal M. Detección de serinocarbapenemasas de clase A y otros mecanismos de resistencia enzimática a $\beta$ lactámicos en cepas de enterobacterias con susceptibilidad disminuida a carbapenémicos, aisladas de pacientes de un hospital universitario de Santiago, Chile. Rev Chilena Infectol. 2014;31(6):682-8.

58. Pérez A, García P, Poggi H, Braun S, Castillo C, Román JC, et al. Presencia de metalo-ß-lactamasas en Pseudomonas aeruginosa resistente a imipenem. Revista médica de Chile. 2008;136(4):423-32.

59. Larios FR. IDENTIFICACIÓN DE GENES RESPONSABLES DE RESISTENCIA A CARBAPENÉMICOS EN CEPAS NOSOCOMIALES DE Pseudomonas aeruginosa AISLADAS EN ALGUNOS HOSPITALES DE MÉXICO. 2009.

60. Bush K, Jacoby GA. Updated functional classification of $\beta$-lactamases. Antimicrobial Agents and chemotherapy. 2010;54(3):969-76.

61. Munoz-Price LS, Poirel L, Bonomo RA, Schwaber MJ, Daikos GL, Cormican M, et al. Clinical epidemiology of the global expansion of Klebsiella pneumoniae carbapenemases. The Lancet infectious diseases. 2013;13(9):785-96.

62. Martínez-Martínez L, González-López JJ. Carbapenemases in Enterobacteriaceae: Types and molecular epidemiology. Enfermedades Infecciosas y Microbiología Clínica. 2014;32:4-9.

63. Yigit H, Queenan AM, Anderson GJ, Domenech-Sanchez A, Biddle JW, Steward CD, et al. Novel carbapenemhydrolyzing $\beta$-lactamase, KPC-1, from a carbapenemresistant strain of Klebsiella pneumoniae. Antimicrobial agents and chemotherapy. 2001;45(4):1151-61.

64. Villegas MV, Lolans K, Correa A, Suarez CJ, Lopez JA, Vallejo M, et al. First detection of the plasmid-mediated class A carbapenemase KPC-2 in clinical isolates of Klebsiella pneumoniae from South America. Antimicrobial agents and chemotherapy. 2006;50(8):2880-2.

65. Monteiro J, Santos AF, Asensi MD, Peirano G, Gales AC. First report of KPC-2-producing Klebsiella pneumoniae strains in Brazil. Antimicrobial agents and chemotherapy. 2009;53(1):333-4.

66. Pasteran FG, Otaegui L, Guerriero L, Radice G, Maggiora $\mathrm{R}$, Rapoport $\mathrm{M}$, et al. Klebsiella pneumoniae Carbapenemase-2, Buenos Aires, Argentina. Emerging infectious diseases. 2008;14(7):1178.

67. Marcano D, De Jesús A, Hernández L, Torres L. Frequency of enzymes associated with reduced sensitivity to beta-lactam antibiotics in enterobacteria isolates, Caracas, Venezuela. Revista Panamericana de Salud Pública. 2011;30(6):529-34.

68. Cifuentes M, Garcia P, San Martín P, Silva F, Zúñiga J, Reyes S, et al. [First isolation of KPC in Chile: from Italy to a public hospital in Santiago]. Revista chilena de infectologia: organo oficial de la Sociedad Chilena de Infectologia. 2012;29(2):224-8. 
69. Togneri AM, Gómez SA, Podestá LB, Pérez MP, Faccone DF, Ríos LE, et al. Diseminación de bla IMP-8 en enterobacterias aisladas en un hospital de Buenos Aires. Revista argentina de microbiología. 2013;45(2):104-9.

70. Guevara A, Sierra CI, de Waard J. Caracterización molecular de Pseudomonas aeruginosa resistentes a carbapenémicos provenientes de cuatro hospitales de Venezuela. Revista chilena de infectología. 2012;29(6):614-21.

71. Nordmann P, Poirel L, Walsh TR, Livermore DM. The emerging NDM carbapenemases. Trends in microbiology. 2011;19(12):588-95.

72. Rocha C, Reynolds ND, Simons MP. Resistencia emergente a los antibióticos: una amenaza global y un problema crítico en el cuidado de la salud. Revista Peruana de Medicina Experimental y Salud Pública. 2015;32(1).

73. Doriaa FAB, Osoriob MÁD, Muñoz ÁB. Asociación Colombiana de Infectología. Infectio. 2013;17(1):35-8.

74. Vila J, Marco F. Lectura interpretada del antibiograma de bacilos gramnegativos no fermentadores. Enfermedades infecciosas y Microbiología clínica. 2010;28(10):726-36.

75. Rasmussen BA, Bush K, Keeney D, Yang Y, Hare R, O'Gara $\mathrm{C}$, et al. Characterization of IMI-1 beta-lactamase, a class A carbapenem-hydrolyzing enzyme from Enterobacter cloacae. Antimicrobial Agents and Chemotherapy. 1996;40(9):2080-6.

76. Sánchez FG, del Castillo BR, Casanova PM, Iglesias MR. Caracterización de blaOXA-48 detectada en cepas clínicas de Enterobacter cloacae aisladas en el sur de España. Enfermedades infecciosas y microbiología clínica. 2012;30(9):584-5.

77. Bou G, Martínez-Beltrán J. Cloning, nucleotide sequencing, and analysis of the gene encoding an AmpC $\beta$-lactamase in Acinetobacter baumannii. Antimicrobial agents and chemotherapy. 2000;44(2):428-32.

78. Lopez-Otsoa F, Gallego L, Towner K, Tysall L, Woodford $\mathrm{N}$, Livermore D. Endemic carbapenem resistance associated with OXA-40 carbapenemase among Acinetobacter baumannii isolates from a hospital in northern Spain. Journal of clinical microbiology. 2002;40(12):4741-3.

79. Yu Y-S, Yang Q, Xu X-W, Kong H-S, Xu G-Y, Zhong B-Y. Typing and characterization of carbapenem-resistant Acinetobacter calcoaceticus-baumannii complex in a Chinese hospital. Journal of medical microbiology. 2004;53(7):653-6.

80. Dalla-Costa LM, Coelho JM, Souza HA, Castro ME, Stier CJ, Bragagnolo KL, et al. Outbreak of carbapenem-resistant Acinetobacter baumannii producing the OXA-23 enzyme in Curitiba, Brazil. Journal of clinical microbiology. 2003;41(7):3403-6.

81. Brown S, Amyes S. The sequences of seven class D $\beta$ lactamases isolated from carbapenem-resistant Acinetobacter baumannii from four continents. Clinical microbiology and infection. 2005;11(4):326-9.

82. Zuñiga AE, Chávez M, Gómez RF, Cabrera CE, Corral RE, López B. Relación entre virulencia y resistencia antimicrobiana en Acinetobacter baumannii. NOVA. 2010;8(14). 